\title{
EL PAPEL DE LA DEA EN LA EMERGENCIA DEL CAMPO POLICIAL ANTIDROGAS EN AMÉRICA LATINA
}

\author{
THE ROLE OF THE DEA IN THE EMERGENCE OF THE \\ FIELD OF COUNTERNARCOTICS POLICING IN LATIN \\ AMERICA
}

\section{LE RÔLE DE LA DEA DANS LA FORMATION D'AGENCES DE POLICE ANTI-NARCOTIQUES EN AMÉRIQUE LATINE}

\author{
Carlos A. Pérez Ricart \\ Universidad Libre de Berlín \\ cperezricart@gmail.com
}

Resumen: Se examinan, aquí, las respuestas institucionales que surgieron en América Latina sobre el tráfico de drogas en la década de los setenta. Se explora, en particular, la emergencia del campo policial antinarcóticos de entonces. Como argumento central, se apunta que las agencias antidrogas de los Estados Unidos —en especial, la Drug Enforcement Administration (DEA) — coadyuvaron a la estructuración del campo policial antinarcóticos en América Latina. A partir de una revisión de distintos fondos documentales, se analizan los orígenes de las instituciones policiacas antidrogas en América Latina, la difusión de las prácticas de desarrollo institucional que emprendió la DEA y la creación de redes policiacas en la región.

Palabras clave: Drug Enforcement Administration (DEA), campo organizacional, militarización, seguridad, política antinarcóticos, policía.

Abstract: In this paper we examine the institutional responses that emerged in Latin America to drug trafficking in the 1970s. It explores, in particular, the emergence of the field of counternarcotics policing at the time. As a central argument, it asserts that us drug agencies-especially the Drug Enforcement Administration (DEA) - helped to structure the field of counternarcotics policing in Latin America. Based on a review of a range of documentary resources, we analyze the origins of counternarcotics institutions in Latin America, the dissemination of institutional development practices undertaken by the DEA, and the creation of police networks in the region. 
Keywords: Drug Enforcement Administration (DEA), organizational field, militarization, security, counternarcotics policy, police.

Traducción de Gonzalo Celorio Morayta

Résumé: On examine ici les réponses institutionnelles contre le trafic de drogues en Amérique latine dans les années 1970, en particulier le surgissement d'agences de police anti-narcotiques à cette époque-là. L'idée centrale de l'article est que les autorités de lutte contre les stupéfiants aux États-Unis -notamment la Drug Enforcement Agency (DEA)- ont contribué à l'organisation de forces policières anti-narcotiques en Amérique latine. L'analyse de plusieurs archives met en évidence l'origine de ces régiments spécialisés dans la lutte antidrogue, la diffusion de pratiques de développement institutionnel promues par la DEA et la création de réseaux policiers dans la région.

Mots clefs: Drug Enforcement Agency (DEA), organisation du terrain, militarisation, sécurité, politique contre les drogues, police.

Traducción de Bernardo Mabire

Fecha de recepción: marzo de 2017

Fecha de aceptación: agosto de 2017 
$\mathrm{E}$ N EL AÑo 1973, se fundó la Drug Enforcement Administration (DEA), organización que concentró las funciones federalmente policiales en lo que atañe a los delitos de drogas en Estados Unidos. La DEA heredó su estructura, funciones y no poco de su personal de dos agencias predecesoras -el Bureau of Narcotics and Dangerous Drugs (BNDD, 19681973) y el Federal Bureau of Narcotics (FBN, 1930-1968)- y atendió la necesidad de establecer una unidad capaz de enfrentar de manera global y permanente lo que en ese entonces se interpretaba como la amenaza de las drogas. ${ }^{1}$

Al comenzar la década de los años setenta, con la excepción de Estados Unidos y Francia, en el resto del mundo las investigaciones antinarcóticas se ejecutaban en pequeñas oficinas entre las policías judicial o nacional de cada país. ${ }^{2}$ Las secciones antidrogas que había carecían de autonomía y entrenamiento especializado; mantenían una plantilla fluctuante y trabajaban con presupuestos reducidos. Así, la irrupción del modelo DEA señaló un antes y un después en el campo policial antidrogas.

Aunque enclavada en el Departamento de Justicia y sujeta legalmente a la Oficina del Procurador General de los Estados Unidos (Attorney General), la DEA mantuvo y desarrolló una serie de facultades que antes sólo disfrutaban parcialmente el FBN y el BNDD: la administración y regulación de precursores químicos y drogas legales para uso médico o científico, la aplicación de leyes federales atinentes al consumo, transporte, comercio y cultivo de drogas, así como el asesoramiento al Departamento de Estado en la conducción de la diplomacia respecto a los estupefacientes. ${ }^{3}$ La DEA introdujo

${ }^{1}$ R. Nixon, "Special Message to the Congress on Drug Abuse Prevention and Control", 17 de junio de 1971.

${ }^{2}$ M. Picini, FBn District Supervisor Rome, Carta a Henry L. Giordano, "Overseas training", 16 de marzo de 1966. [RG 170, caja 49, carpeta 2, NARA].

${ }^{3}$ C. A. Pérez Ricart, Las agencias antinarcóticos de los Estados Unidos y la construcción transnacional de la guerra contra las drogas en México (1938-1978), tesis, Universidad Libre de Berlín, 2016, cap. IV. Véase también P. Rachal, 
un doble sistema de operación basado, por un lado, en la división del espacio geográfico a partir de oficinas distritales y, por otro, en la persecución puntual de redes de narcotraficantes sin menoscabo del territorio. Mantuvo su influencia en la formación de la política exterior de los Estados Unidos en temas de drogas, así como en la vida diaria de instituciones supranacionales dedicadas al asunto. En Estados Unidos, fundó asociaciones profesionales y alianzas duraderas con grupos conservadores. Como el FBN, apenas si estuvo expuesta al control de comités del Congreso de Estados Unidos; mantuvo cierto antagonismo con las instituciones del sector de la salud y luchó por que se le concediera de facto la autoridad para decidir sobre todo lo relacionado con la política de drogas local y federalmente. ${ }^{4}$ Sin embargo, la impronta más característica de la DEA fue su estrategia de internacionalización de la "guerra contra las drogas", que llevó a cientos de sus agentes a operar en el extranjero y a tratar con policías y altos mandos de otros países. ${ }^{5}$

La bibliografía académica ha sugerido que la DEA tuvo un papel central en el impulso de una política de drogas punitiva y militarizada alrededor del mundo. ${ }^{6}$ Una afirmación parecida se ha hecho sobre América Latina. ${ }^{7}$ Según esta interpreta-

Federal Narcotics Enforcement: Reorganization and Reform, Boston, Auburn House Publishing Company, 1982.

${ }^{4}$ Pérez Ricart, op. cit., cap. IV.

${ }^{5}$ E. Nadelmann, "The DEA in Latin America: Dealing with Institutionalized Corruption”, Journal of Interamerican Studies and World Affairs, vol. 29, núm. 4, 1987, pp. 1-39. Para una visión interna, cf. E. A. Heath, Mexican Opium Eradication Campaign, tesis, California State University, 1981.

${ }^{6}$ Efectivamente, casi toda la evidencia empírica se ha recabado a partir de la experiencia europea. Véase P. Andreas y E. Nadelmann, Policing the Globe: Criminalization and Crime Control in International Relations, Oxford, University Press, 2008.

${ }^{7}$ Cf. M. C. Toro, Mexico's “War" on Drugs: Causes and Consequences, BoulderLondres, Lynne Rienner Publishers, 1995, y M. Serrano, "Unilateralism, Multilateralism, and US Drug Diplomacy. The Politics of the Certification Process in Latin America", en Y. Foong Khong y D. Malone (eds.), Unilateralism and U.S. Foreign Policy, Boulder, Lynne Rienner Publishers, 2003, pp. 117-136. 
ción, la agencia habría impulsado, mediante un abanico amplio de estrategias -que van del uso de formas suaves de difusión de modelos a la utilización de mecanismos de presión-, el surgimiento y fortalecimiento de organizaciones policiacas similares a la DEA. A pesar de que esa interpretación apenas ha sido rebatida, tampoco ha sido probada del todo.

Si bien algunos estudios de caso han mostrado el perfil de la DEA como actor político transnacional y su enorme influencia en el campo de políticas antidrogas en periodos y países específicos, ${ }^{8}$ hasta ahora no se ha inquirido en el papel concreto que desempeñó la agencia en la reestructuración de los cuerpos antidrogas de América Latina en la década de los años setenta. Así, este artículo busca responder, con base en la revisión de archivos y fondos documentales, a la pregunta de cuáles fueron las funciones de la DEA en el proceso de emergencia de policías antinarcóticos en América Latina.

$\mathrm{Al}$ dar respuesta a la interrogante, se pretende aportar elementos para una comprensión más amplia sobre la tarea policial en América Latina y las fuentes transnacionales que la estructuraron. Al mismo tiempo, en el artículo se busca hacer una contribución al campo de investigación sobre las relaciones cívico-militares en América Latina en un momento complejo y caracterizado por el establecimiento de gobiernos de facto. Además, este trabajo interviene directamente en la agenda de la nueva sociología institucional centrada no solamente en las formas similares que adquieren las organizaciones a partir de procesos de difusión, sino en los rasgos híbridos que éstas adquieren como resultado de la combinación entre flujos transnacionales y contextos locales.

La hipótesis central del artículo se divide de la siguiente manera: al participar como catalizadora de tres procesos -la producción de expertos y especialistas, la organización de

${ }^{8}$ El estudio clásico sigue siendo el de E. Nadelmann, Cops across Borders: The Internationalization of U.S. Criminal Law Enforcement, Pennsylvania, State University Press, 1993. 
asociaciones y redes especializadas y la consolidación de una élite profesional-, la DEA fungió como actor principal en el proceso de estructuración del campo policial antidrogas en América Latina. Tales procesos condujeron a una reconfiguración compleja de las organizaciones policiacas en el subcontinente, caracterizada por la combinación entre dinámicas homogeneizadoras y locales.

El artículo se estructura en cinco secciones principales. El marco conceptual presenta la imagen de campo organizacional en cuanto unidad analítica, así como una breve revisión y síntesis de los mecanismos que explican el cambio institucional. En esta primera parte, se intenta vincular la bibliografía sobre campos organizacionales con discusiones más generales sobre la transferencia y difusión de políticas. En el segundo apartado, con el propósito de delinear los contornos del asunto por tratar, se describe la emergencia de las primeras policías dedicadas al tema de drogas en América Latina antes de 1973. En el tercero, se analiza la función de la DEA en América Latina en cuanto organización central del campo. En el cuarto, se describe la estructuración del cuerpo policial antidrogas en América Latina en los años posteriores a la fundación de la agencia estadounidense. Finalmente, en el quinto, se analizan los tres tipos de procesos impulsados por la DEA, ya citados. En la conclusión se presentan posibles líneas futuras de investigación y una reflexión crítica sobre el papel de la DEA como difusor y promotor de patrones de gobernanza en el tema de las drogas.

LA IDEA DE CAMPO ORGANIZACIONAL Y LOS MECANISMOS DE CAMBIO INSTITUCIONAL

El argumento de este artículo se enmarca en el nuevo institucionalismo: una perspectiva teórica con capacidad explicativa para identificar las formas en que las organizaciones están conectadas con los ambientes institucionales que las rodean. Como punto de partida, se retoman las contribucio- 
nes de Walter Powell y Paul Dimaggio, para quienes el cambio en la estructura formal, programa, prácticas y objetivos de una organización ocurre como resultado de dinámicas institucionales y no a causa de consideraciones de eficiencia. El interés de su investigación, así como de la tradición neoinstitucional en la sociología, se concentró en el estudio de los procesos de homogenización derivados de procesos de difusión entre organizaciones -el llamado isomorfismo institucional. Punto esencial en el planteamiento de Dimaggio y Powell fue el concepto de campo organizacional; esto es "aquellas organizaciones que, en conjunto, constituyen un área reconocida de la vida institucional". ${ }^{9}$ Como toda aproximación inserta en el concepto campo, se parte del presupuesto de que el objeto de estudio no puede explicarse solamente por sus características internas o por su localización física, sino por su espacio social definido.

Dimaggio y Powell sostienen que en las etapas iniciales de su ciclo de vida, las organizaciones muestran una "diversidad considerable de enfoques y formas". ${ }^{10}$ Sin embargo, el aumento en el grado de interacción entre éstas, el surgimiento de estructuras interorganizacionales de dominio, el incremento en el flujo de información y el "desarrollo de una conciencia común entre las organizaciones de que participan en una empresa común" llevan a la institucionalización del campo organizacional, la cual produce un "impulso inexorable hacia la homogenización”. ${ }^{11}$ Así, según este principio, a medida que los campos organizacionales se tornan más estructurados, los modelos organizativos se hacen más homogéneos. ${ }^{12}$

${ }^{9}$ P. Dimaggio y W. Powell, "Retorno a la jaula de hierro. El isomorfismo institucional y la racionalidad colectiva en los campos organizacionales", en W. Powell y P. Dimaggio (eds.), El nuevo institucionalismo en el análisis organizacional, México, Fondo de Cultura Económica, 1999, p. 106.

${ }^{10}$ Ibidem, p. 105.

${ }^{11}$ Ibid., pp. 105-106.

${ }^{12}$ R. W. Scott, "Retomando los argumentos institucionales", en W. Powell y P. Dimaggio (eds.), El nuevo institucionalismo en el análisis organizacional, México, Fondo de Cultura Económica, 1999, p. 224. 
El proceso, sin embargo, es multiforme: mientras que las organizaciones periféricas están mucho más expuestas a los procedimientos de homogenización, las organizaciones centrales y más antiguas, lejos de ajustarse a ellos, llegan a dominarlos. ${ }^{13}$

En la búsqueda por identificar las fuerzas que operan detrás de los procesos de homogenización, la bibliografía neoinstitucional ha identificado tres tipos de mecanismos: coercitivos, normativos y de emulación. ${ }^{14}$ Con mecanismos de coerción se hace referencia a "presiones formales e informales que sobre unas organizaciones ejercen otras de las que dependen". ${ }^{15}$ Engloban todas las interacciones, sutiles y explícitas, que obligan a otras organizaciones a modificar sus prácticas, programas, estructuras y objetivos. Con mecanismos normativos se hace referencia a los procesos de socialización a los que están expuestos actores clave de cada organización. Su análisis destaca la relevancia que tienen las redes profesionales y epistemológicas en la difusión de modelos y prácticas, normalización de expectativas, así como en reproducción de significados de comprensión común. Por último, es posible explicar el cambio institucional a partir de mecanismos miméticos o de emulación. Aunque son similares a los mecanismos normativos, en este caso la difusión no pasa necesariamente por un proceso de socialización, sino por la emulación de lo que se percibe como avanzado, eficiente o moralmente correcto. La bibliografía coincide en señalar el desencadenamiento de mecanismos miméticos en situaciones de incertidumbre y en circunstancias de búsqueda de respuestas a problemas comunes, que lleva a las organizaciones, aun sin comprender las razones del éxito de otras, a terminar adoptando los modelos de las organizaciones centrales.

En este artículo me concentraré en explorar el funcionamiento de mecanismos normativos y de emulación en el

13 Dimaggio y Powell, art. cit., p. 108.

14 Aunque las nomenclaturas cambian según el autor, sigo aquí las categorías de ibid., p. 109.

15 Idem. 
ámbito de la emergencia del campo policial antidrogas en América Latina. El examen de los mecanismos de coerción queda fuera del análisis por ser éstos los que mayor atención han recibido en lo que respecta a la relación, en clave narcóticos, entre Estados Unidos y América Latina. ${ }^{16}$ Según se ha señalado, y no sin razón, la DEA habría recurrido a "una lista bien surtida y suficientemente documentada de instrumentos de presión” para promover el cambio institucional en el subcontinente. ${ }^{17}$ Sin pretender obviar que mucho hubo de coerción en el desarrollo de la relación entre las agencias estadounidenses y los gobiernos latinoamericanos, este artículo se detiene a estudiar las formas suaves en que el modelo de la DEA fue difundiéndose a lo largo del subcontinente -una dimensión mucho menos estudiada y posiblemente más relevante.

Es preciso señalar que la activación de mecanismos normativos y de emulación no implica que éstos puedan funcionar de manera independiente ni que lleven irreductiblemente a procesos de homogenización. ${ }^{18}$ Las razones pueden ser varias: el desinterés de la organización dominante del campo, la inercia institucional de las organizaciones, los pocos in-

${ }^{16}$ Por ejemplo, R. Crandall, Driven by Drugs: U.S. Policy Towards Colombia, Boulder, Lynne Rienner Publishers, 2002, y C. Youngers y E. Rosin (eds.), Drugs and Democracy in Latin America: The Impact of U.S. Policy, Boulder, Lynne Rienner Publishers, 2005. Para el caso de México, cf. F. Enciso, "Régimen global de prohibición, actores criminalizados y la cultura del narcotráfico en México durante la década de 1970”, Foro Internacional, vol. 49, núm. 3, 2009, pp. 595-637.

${ }^{17}$ La cita refiere al caso mexicano, pero me parece interesante para ilustrar el argumento. Véase Toro, "Estrategias mexicanas de negociación: el caso del narcotráfico", en I. Bizberg (ed.), México ante el fin de la guerra fría, México, El Colegio de México, 1999, p. 328. Para una visión más general del mismo asunto, cf. J. Gerber y E. Jensen (eds.), Drug War, American Style: The Internationalization of Failed Policy and its Alternatives, Nueva York, Garland Publishing, 2001.

18 Pueden incluso desencadenar procesos diferenciadores. Véase, por ejemplo, J. Beckert, "Institutional Isomorphism Revisited: Convergence and Divergence in Institutional Change", Sociological Theory, vol. 28, núm. 2, 2010, pp. 150-166. 
centivos de los tomadores de políticas para modificar los ensamblajes institucionales, así como otros procesos asociados a la idea de trayectorias dependientes (path dependence). Más aún, incluso en circunstancias en que el flujo de información es constante, pues las condiciones internas lo permiten, las organizaciones difícilmente llegan a asimilarse por completo. Por lo general, cualquier reconfiguración institucional tiene como resultado la emergencia de modelos híbridos en los que conviven lógicas locales con presiones externas. Conceptos como bricolage, localization y translation -cada uno anclado a tradiciones epistemológicas distintas- refieren a la combinación de principios y prácticas difundidos por actores transnacionales con las condiciones locales y pretenden no solamente captar el maridaje y dinamismo de políticas, sino la necesidad metodológica de identificar tanto los modelos difundidos, como los contextos institucionales que (no) permiten la implementación de nuevas ideas. ${ }^{19}$ Como se mostrará a lo largo del estudio, en última instancia, el grado de exposición de las lógicas locales a la influencia de actores transnacionales es una cuestión que sólo puede resolverse a partir de la investigación empírica.

PRIMERA ETAPA DEL CICLO DE VIDA DEL CAMPO POLICIAL antinarcóticos EN AMÉrica Latina

Hacia la década de los años veinte del siglo pasado, con pocas excepciones, en todos los países de América Latina se habían

${ }^{19}$ J. Campbell, "Institutional Reproduction and Change", en G. Morgan et al. (eds.), The Oxford Handbook of Comparative Institutional Analysis, Oxford, University Press, 2010, pp. 87-116, y A. Acharya, "How Ideas Spread: Whose Norms Matter? Norm Localization and Institutional Change in Asian Regionalism", International Organization, vol. 58, núm. 2, 2004, pp. 239-275. Perú y Bolivia fueron más renuentes que el resto de los Estados a aceptar las directrices internacionales. Véase P. Gootenberg, "Secret Ingredients: The Politics of Coca in US-Peruvian Relations, 1915-65", Journal of Latin American Studies, vol. 36, núm. 2, 2004, pp. 233-265. 
establecido disposiciones legislativas que castigaban parte o la totalidad de la cadena económica que une los puntos de producción con los de consumo de drogas. ${ }^{20}$ Con las leyes punitivas se crearon, casi de forma paralela, organizaciones encargadas de perseguir los delitos de drogas: por lo general, pequeñas oficinas ancladas a los departamentos de salubridad pública.

La creación de agencias especializadas fue una de las políticas públicas acordadas en el artículo XV de la Convención de Ginebra de 1931.21 Todos los Estados firmantes -once de ellos latinoamericanos- se comprometieron a mantener una oficina autónoma y dedicada solamente a la persecución de narcóticos. En la práctica, sin embargo, tal directriz no supuso, en términos de Powell y Dimaggio, un impulso inexorable hacia la homogenización; las instituciones de salud conservaron autoridad sobre el tema. En México, por ejemplo, la jurisdicción sobre "asuntos de drogas heroicas" continuó a cargo de una pequeña oficina al interior del Departamento de Salubridad Pública. ${ }^{22}$ En México, como en la mayoría de los países en América Latina, la predominancia de los inspectores de narcóticos o policías sanitarios -los nombres son intercambiables- sobre asuntos de droga no evitó la existencia de un aparato policial alterno. En casi todos los casos, los sistemas judiciales se enfrentaron al siguiente problema: las policías sanitarias no podían procesar criminales, sólo detenerlos. Ello hizo necesaria la creación de unidades que asumieran la función procesal, investigativa y persecutoria. Este otro ente policiaco dependía del país y su estructura penal,

${ }^{20}$ Un buen análisis histórico de la materia puede encontrarse en B. Caiuby Labate y T. Rodrigues, "Política de drogas y prohibición en las Américas", en B. Caiuby Labate y T. Rodrigues (eds.), Drogas, política y sociedad en América Latina y el Caribe, México, CIDE, 2015, pp. 29-52.

${ }^{21}$ Véase Liga de las Naciones, Convention for Limiting the Manufacture and Regulating the Distribution of Narcotic Drugs, and Protocol of Signature, Geneva, 1931.

${ }^{22}$ Véase Poder Ejecutivo, Dof, "Código Sanitario de los Estados Unidos Mexicanos”, 31 de agosto de 1934. 
por lo que casi siempre estuvo situado en una oficina policial subordinada a la Policía Nacional o a la Policía Judicial. Así, por lo menos hasta la mitad de la década de los años cuarenta, los ensamblajes coercitivos de los Estados latinoamericanos tuvieron que padecer la turbia situación que implicaba discernir las peculiaridades de la droga, ya que había el dilema de si la droga era un problema psiquiátrico-toxicológico o de seguridad. En cada país se adoptaron medidas muy distintas, enfoques diferentes y formas de organización heterogéneas. El campo organizacional estaba en las primeras etapas de su ciclo de vida.

Conforme pasaron los años, las instituciones de salud pública fueron concentrándose cada vez más en aquellos aspectos de la política de drogas que menos tenían que ver con la cuestión policiaca. Sus inspectores continuaron administrando las instancias de importación y exportación de precursores químicos, así como la venta legal de narcóticos; sin embargo, el lado coercitivo de la política de drogas quedó libre para las policías judiciales o nacionales. Entre las razones para esa primera sustitución de los actores del campo se encuentran la presión de un régimen global de prohibición cada vez más exigente y la incipiente, pero también creciente presión sobre los Estados latinoamericanos por parte del FBN y la Oficina de Aduanas de los Estados Unidos. ${ }^{23}$

El primer proceso de afianzamiento de la estructura policial en el área de políticas de drogas fue bastante dispar en América Latina. En los países que comenzaban a posicionarse como puntos clave en la ruta de la droga proveniente de Asia, se crearon oficinas a instancias del propio FBN. Así, por ejemplo, en 1944 se instituyó en Cuba el Buró de Narcóticos de Cuba, y en 1943, la Policía Federal de Narcóticos (PFN) en México, al mando de un coronel con dieciséis hombres a su disposición. Aunque en la práctica ambas organizaciones es-

${ }^{23}$ Para la idea de régimen global de prohibición, véase Nadelmann, "Global Prohibition Regimes: The Evolution of Norms in International Society”, International Organization, vol. 44, núm. 4, 1990, pp. 479-526. 
taban muy lejos de parecerse al FBN -el PFN, por ejemplo, seguía subordinado a la Secretaría de Salubridad y Asistencia-, tan sólo su nomenclatura eliminó para siempre la idea del inspector o policía sanitario. En la mayoría de los países de América Latina no se crearon unidades con nombres similares, sino hasta mediados de la década de los años sesenta. En Chile, por ejemplo, se creó en 1964 la primera agencia policiaca especializada en temas de drogas en América del Sur: la Brigada de Represión del Tráfico de Estupefacientes y Juegos de Azar (BEJA), correspondiente a la Policía de Investigaciones. Conformada por media docena de hombres, la BEJA mantuvo desde sus orígenes estrecha relación con el FBN y, más tarde, con el BNDD. ${ }^{24}$

En América Central, el proceso fue relativamente homogéneo y estuvo asociado a la necesidad de responder a las demandas del FBN, y luego del BNDD, de mantener un interlocutor en la región. Por tanto, en Guatemala se fundó, en 1966, la Sección de Control de Drogas y Narcóticos en el Departamento de Justicia. En Costa Rica, dos años después, se creó la Dirección de Narcóticos en el Ministerio de Seguridad Pública, anclada en la Guardia Civil. El resto de los países centroamericanos constituyó oficinas semejantes, cuya característica más evidente fue su irrelevancia en la profesionalización y el liderazgo militar.

Todos estos procesos de reorganización se dieron antes de la emergencia de dos dinámicas separadas. Por un lado, el surgimiento de gobiernos de facto en toda la región, cuyo tinte autoritario cristalizó en la politización del sistema penal, el dogmatismo doctrinal y la militarización de los cuerpos de seguridad pública. ${ }^{25}$ Por otro, la cada vez mayor relevancia de la región como exportadora de opio y productora de drogas ilegales. En ello, dos eventos fueron funda-

${ }^{24}$ Véase M. Fernández Labbé, "La imaginación policial: la construcción del narcotráfico en Chile, 1900-1950", en D. Palma Alvarado (ed.), Delincuentes, policías y justicias: América Latina, siglos XX y XXI, Santiago de Chile, Universidad Alberto Hurtado, 2015, pp. 330-356.

${ }^{25} \mathrm{~J}$. M. Rico, Justicia penal y transición democrática en América Latina, México, Siglo XXI, 1997, p. 11. 
mentales: la inmovilización de la conexión francesa-una red de narcotráfico que durante lustros llevó opio proveniente de Medio Oriente a Nueva York- y la restricción oficial en Turquía de la producción de opio en 1972. Hacia 1973 se estimaba que de América Latina provenían aproximadamente la mitad del opio y toda la cocaína que llegaban a los Estados Unidos. ${ }^{26}$ Diferentes reportes oficiales de la época dan cuenta de sembradíos de amapola y mariguana en regiones de Ecuador, Colombia, Costa Rica y México, así como de plantíos de hoja de coca en la zona andina -Chile, Perú, Bolivia, Ecuador y Colombia. En este entorno de politización extrema de los sistemas de seguridad interna y de aumento de la producción y transporte de droga en América Latina, se creó la DEA en los Estados Unidos.

\section{UNA ORGANIZACIÓN GENTRAL EN EL CAMPO: LA DEA en AmÉrica Latina}

¿Llevó la presencia transnacional de la DEA al surgimiento de agencias semejantes en América Latina? Antes de avanzar hacia esa cuestión conviene discutir el tema del peso específico de la DEA y sus agencias predecesoras en el resto de la estructura burocrática de los Estados Unidos en la época.

$\mathrm{Al}$ iniciar la década de los años setenta, el combate de los Estados Unidos en América Latina en contra de las drogas estaba encabezado por tres organizaciones distintas: el BNDD, la Office of Public Safety (ops) y la Oficina de Aduanas. Las embajadas, por su parte, contaban con un grupo especializado que incorporaba a representantes de estas organizaciones, así como personal del Departamento de Estado y agencias de seguridad. Tanto el grupo de la embajada como el resto de las

${ }^{26}$ M. F. Murphy y R. H. Steele (eds.), The World Narcotics Problem: The Latin American Perspective. Report of Special Study Mission to Latin America and the Federal Republic in Germany, Washington D.C., U.S. Government Printing Office, 1973, p. 1. 
organizaciones respondían directamente al Cabinet Committee on International Narcotics Control (CCINC), cuerpo organizado en 1971 por el Departamento de Estado para coordinar la guerra contra las drogas diseñada por Nixon. Aunque el CCINC mantuvo entre 1971 y 1978 la facultad para deliberar sobre las estrategias y objetivos más generales de la política antinarcóticos en el exterior, en la práctica eran las agencias -primero el BNDD y después la DEA- las organizaciones que mayor influencia tuvieron en la planeación de la política exterior en clave narcóticos. La influencia estribaba en que los inputs con los que se establecía la política del cainc para cada país venían mayoritariamente de la información y diagnósticos de los funcionarios de las agencias. ${ }^{27}$

En 1974, por primera vez en la historia, el Congreso de los Estados Unidos aprobó un presupuesto diseñado exclusivamente para la creación de un programa internacional antinarcóticos (International Narcotics Control: INC). Ese año se asignaron 42.5 millones de dólares para este propósito; gran parte del dinero se transfirió directamente a otros gobiernos para la compra de aviones, helicópteros, armas o para impulsar programas de sustitución de cultivos. Ya en la elección del destino de aquellos recursos participó la DEA; sin embargo, la agencia disfrutó además de una suerte de caja chica de fondos provenientes de un acuerdo con el Departamento de Estado que ascendía a más de once millones de dólares. ${ }^{28}$ En principio, la DEA disfrutaba de autonomía para dirigir aquel dinero a las áreas que considerase prioritarias.

Más importante que el presupuesto era la expansión territorial de la DEA alrededor del mundo. En ello, ninguna otra organización pudo hacerle sombra. Conforme avanzó la década de los años setenta, su presencia en América Latina aumentó de forma dramática. Hacia 1973, el BNDD mantenía

27 Pérez Ricart, op. cit., cap. IV.

${ }^{28}$ United States General Accounting Office, "Drug Control in South America Having Limited Success: Some Progress but Problems are Formidable", Washington, D.C., GAO, marzo de 1978, p. 2. 
dos oficinas regionales en América Latina: una en Buenos Aires y otra en la Ciudad de México. ${ }^{29}$ Además, contaba con una red compuesta por una docena de oficinas distritales subordinadas a aquéllas. ${ }^{30} \mathrm{~A}$ la oficina regional en la capital argentina estaban asignados dieciséis agentes: cinco a Buenos Aires y los once restantes a Paraguay, Colombia, Brasil, Venezuela, Perú, Bolivia, Ecuador y Chile. Asimismo, la oficina de la Ciudad de México tenía asignados quince agentes, cuya área de jurisdicción incluía México y América Central, con la excepción de Panamá, país en el que se constituyó una oficina autónoma con dos agentes asignados. A partir del verano de 1973, no solamente todas las oficinas del BNDD se reconvirtieron en "filiales" de la DEA; se fundaron varias más de forma inmediata y se aumentó la plantilla de agentes antinarcóticos de forma considerable. El número de agentes especiales de la DEA en América Latina rondó en torno a los sesenta entre 1973 y $1978 .{ }^{31}$ Ello no incluye los agentes, quienes, por temporadas delimitadas, viajaban a realizar tareas específicas. En México llegaron a ser decenas durante las campañas de erradicación a mediados de los años setenta. ${ }^{32}$

No todos los países presentaban el mismo grado de relevancia para la agencia. Las áreas de prioridad se definían no solamente por la importancia relativa de cada país en la cadena del tráfico de drogas, sino por cuestiones políticas que se dirimían internamente entre la DEA, el Departamento de Estado y el resto de las agencias relacionadas. Aun así, durante la década de los años setenta, cuatro fueron los países a que la DEA destinó la mayor parte de su presupuesto y recursos humanos: México, Bolivia, Colombia y Perú. En una segunda

${ }^{29}$ En septiembre de 1974, la oficina regional en América Latina cambió de Buenos Aires a Caracas.

${ }^{30}$ Por orden de fundación: Monterrey, Lima, Guadalajara, Santiago, Brasilia, Hermosillo, Ciudad de Panamá, Asunción, Caracas, La Paz, Bogotá y Quito. En 1973 se establecieron las oficinas de Mazatlán y Montevideo.

${ }_{31}$ Cálculo del autor con base en diferentes reportes oficiales.

32 Pérez Ricart, op. cit., cap. VI. 
categoría estaban Argentina, Brasil, Ecuador, Guatemala y Venezuela.

En general, es posible rastrear una estrategia constituida por dos componentes. En una primera fase, los agentes y funcionarios de la DEA buscaron fortalecer relaciones con los actores clave de la política antidrogas de cada país y avanzar en ciertos aspectos: la reforma a cierta ley, la complicidad de policías locales con la agencia o la institucionalización de marcos específicos para transferir recursos económicos. Más adelante, se pasaba a la segunda fase de la estrategia: la del desarrollo institucional. Esto es, se procuraba apoyar a cada gobierno en la formación de sistemas de coordinación y control de todas las organizaciones inmersas en el campo de políticas antidrogas. En el mejor de los casos, debía fundarse una agencia especializada y ajena a los vaivenes políticos del momento. Idealmente, las unidades antinarcóticos, además de ser autónomas, debían ser civiles. Ése era el modelo de la DEA y así buscó impulsarlo la agencia en el resto del continente. Sin embargo, las circunstancias hacían difícil copiar el esquema: las policías latinoamericanas tenían, ya desde el siglo XIX, un fuerte elemento militar que antecede, por mucho, la internacionalización de la política de drogas.

\section{LA ESTRUCTURACIÓN DEL CAMPO POLICIAL ANTIDROGAS EN AMÉrica LATiNa EN LA DÉCADA DE LOS AÑos SETENTA}

Como se señaló supra, a principios de la década de los años setenta había aún diversidad considerable de enfoques y formas en que se estructuraban las organizaciones policiacas concentradas en temas de drogas en América Latina. Aquella situación, sin embargo, no tardaría en cambiar. En un plazo cortísimo emergieron, en todos los países de la región, organizaciones más o menos especializadas en temas de drogas. Las formas organizacionales emergentes fueron resultado de dos procesos: por un lado, las dinámicas derivadas de los mecanismos normativos y de emulación impulsados por la 
DEA (véase infra) y, por otro, la fuerte presencia del sector militar en los ensamblajes coercitivos de los Estados latinoamericanos de la época. A continuación, se presentará una breve descripción de los cambios más notables durante el periodo.

A partir de una reforma en 1972, se creó en la Policía Nacional de Colombia una unidad antidrogas en la División de Información, Policía Judicial y Estadística Criminal (DIPEC o F-2). La nueva organización contó con diez tenientes y cuarenta suboficiales ${ }^{33}$ y compartió funciones y jurisdicción con la vieja oficina del Departamento Administrativo de Seguridad (DAS), de cuyo compromiso en el tema de drogas dudaban los estadounidenses. ${ }^{34}$ A principios de 1978 ocurrió una segunda reorganización que, como en los Estados Unidos, llevó las tareas antinarcóticas a la oficina del procurador general de la República. Con sus casi ochenta agentes, la nueva unidad permitió al Estado colombiano extender su política antidrogas a todas las regiones del país. ${ }^{35}$ Desde los Estados Unidos, el proceso de centralización se tuvo por un triunfo de su diplomacia en el área. ${ }^{36}$

A principios de 1973, con veinte hombres, se afianzó en Panamá, en reemplazo de la otrora dominante sección antidrogas de la Guardia Nacional, la unidad antinarcóticos del Departamento Nacional de Investigaciones. Ese mismo año se creó en Bolivia la Dirección Nacional de Control de Sustancias Peligrosas (DNCSP) que, aunque dependiente del Ministerio del Interior, Migración y Justicia, siempre tuvo jefes militares: oficiales, tenientes y capitanes del Ejér-

${ }^{33}$ Office of Public Safety, "Termination Phase-Out Study: Public Safety Project Colombia", abril de 1974, p. 25.

${ }^{34}$ Murphy y Steele (eds.), op. cit., p. 28.

35 Embajada de los Estados Unidos en Colombia, Carta al Departamento de Estado, "Creation of Special Narcotics Unit in Attorney [limited official use]", 1977BOGOTA11749, Wikileaks PlusD, Carter Cables, 17 de diciembre de 1977.

${ }^{36}$ United States General Accounting Office, "Drug Control in South America...", p. 14. 
cito boliviano que, a mediados de la década, sumarían unos cincuenta elementos. ${ }^{37}$ Cabe apuntar que la DNCSP reemplazó a la Oficina Nacional de Narcóticos incorporada antiguamente en la Guardia Nacional de Seguridad Pública, que a su vez había sustituido a una pequeña oficina de asuntos narcóticos supeditada a la Dirección de Investigación Nacional (DIN).

En Argentina, la Sección de Toxicomanías de la PFA, que a comienzos de la década "tenía alrededor de cuarenta hombres y tres vehículos a su disposición”, 38 pasó a convertirse, en 1975, en la División de Drogas Peligrosas de la PFA, organización que trabajó con la DEA y la Gendarmería argentina en los principales casos de narcotráfico en el país. En Perú se constituyó, también en 1975 y bajo el mando de generales, la Dirección de Investigación de Tráfico Ilícito de Drogas (DINTID) en la Policía de Investigaciones (PIP), y en 1978, se le dio jurisdicción absoluta en investigación de tráfico de narcóticos; para entonces contaba con ciento cuarenta y dos hombres en Lima y catorce en el interior del país. ${ }^{39}$ En Chile, la ya citada BEJA se convirtió, en 1975, en el Departamento de Narcóticos y Drogas Peligrosas. Además de mantenerse en la Policía de Investigaciones, por entonces ya incorporada al Departamento de Defensa, compartió facultades antidrogas con cierta unidad de los Carabineros de Chile -Séptima Sección de Investigaciones Especiales (OS-7). La Embajada de los Estados Unidos consideraba "indeseable" tal duplicación de funciones, pero reconocía que, "dadas las circunstancias" (del golpe de Estado), ese tipo de

${ }^{37}$ Embajada de los Estados Unidos en La Paz, Carta al Departamento de Estado, “DEA \& Customs CCINC Training”, 1974LAPAZ06445, Wikileaks PlusD, Kissinger Cables, 4 de octubre de 1974.

${ }^{38}$ F. Mauro e I. Ramírez, Historia de la droga en la Argentina. De la cocaína legal y los fumaderos a los narcos y las metanfetaminas, Buenos Aires, Aguilar, 2015, p. 219.

39 "Convenio de proyecto entre el gobierno de los Estados Unidos de América y el gobierno del Perú”, El Peruano, 29 de agosto de 1984, p. 17. 
configuración era inevitable. ${ }^{40}$ En Guatemala, la reorganización en 1978 de la antigua Sección de Control de Drogas y Narcóticos del Departamento de Justicia significó su traslado, bajo el nombre de Sección de Control de Narcóticos, a la Dirección General de la Policía Nacional. ${ }^{41}$ Contaba con unos veinte elementos de campo, casi todos entrenados en materia de antinarcóticos por la DEA. ${ }^{42}$ La agencia estadounidense interpretó esta reestructuración institucional como el resultado de sus continuas conversaciones con funcionarios guatemaltecos. ${ }^{43}$ Reorganización muy semejante a la de Guatemala fue la que padeció la unidad antidrogas de El Salvador, ${ }^{44}$ la cual, compuesta por quince elementos, fue implantada en el Departamento de Investigaciones de la Policía Nacional en 1978. En Nicaragua, los asuntos antidrogas pasaron en 1976 a la jurisdicción de la Oficina Nacional de Narcóticos de la Policía Nacional, cuerpo militarizado dependiente de la Guardia Nacional. En Costa Rica, el cuerpo antinarcóticos se reorganizó en 1977 para formar parte del Organismo de Investigación Judicial, una suerte de Policía Judicial, auxiliar de los tribunales penales y del Ministerio Público. ${ }^{45}$ Aunque con presupuesto limitado, la DEA acom-

${ }^{40}$ Embajada de los Estados Unidos en Santiago, Carta al Departamento de Estado, "Nomination for Foreign Executive Briefing Program [limited official use]", 1976SANTIA00189, Wikileaks PlusD, Kissinger Cables, 9 de enero de 1976.

${ }^{41}$ La Policía Nacional y sus estructuras, Guatemala, Archivo Histórico de la Policía Nacional, 2010, pp. 72-73.

42 Embajada de los Estados Unidos en Guatemala y DEA HQS, "Request for advanced narcotics training at Guatemala [limited official use]", 1976GUATEM06877, Wikileaks PlusD, Kissinger Cables, 4 de octubre de 1974 .

${ }^{43}$ Embajada de los Estados Unidos en Guatemala, Carta a DEA HQS, "Advanced DEA International Training School [limited official use]", 1978GUATEM01308, Wikileaks PlusD, Carter Cables, 3 de marzo de 1978.

${ }^{44} \mathrm{Id}$.

${ }^{45}$ Embajada de los Estados Unidos en San José, Carta a DEA HQS, "DEA In-country training for Central America", 1976SANJO00674, Wikileaks PlusD, Kissinger Cables, 10 de febrero de 1976. 
pañó aquel proceso de reestructuración. ${ }^{46}$ En Honduras, hacia 1976, la mayor oficina antinarcóticos estaba subordinada a la Dirección General de Investigación Nacional, Fuerza de Seguridad Pública (FUSEP), un cuerpo militarizado y anexo a las Fuerzas Armadas hondureñas. En abril de 1978, aproximadamente, se estableció un cuerpo independiente antidrogas con alrededor de una veintena de funcionarios. Los Estados Unidos apoyaron económicamente este esfuerzo de reorganización y mostraron especial interés en que la nueva unidad no respondiera directamente a FUSEP, sino a los mandos que estimaban más confiables. ${ }^{47}$ Los casos de Brasil, Paraguay, México y Venezuela siguieron derroteros similares.

Desde una perspectiva más general, es posible señalar las siguientes características comunes para todos los países de América Latina: en todos los casos se invirtieron más dinero y recursos humanos en el control antidrogas. El grado y velocidad con que se hizo dependió en gran medida del financiamiento estadounidense. Donde hubo presupuesto para sueldos, compra de armas, automóviles y equipo de telecomunicaciones, también hubo reconfiguraciones institucionales más profundas. En algunos casos -Colombia y Bolivia- se duplicó el personal en un periodo de sólo dos años. ${ }^{48}$ A pesar de no tener edificios o casas de seguridad independientes de las policías nacionales o judiciales, los agentes antidrogas, en casi todos los casos, gozaron de un incremento en el salario en relación con el resto de las fuerzas de seguridad. Todas estas medidas contribuyeron a mejorar la percepción que se tenía de los policías antinarcóticos en cada región, además

${ }^{46}$ Embajada de los Estados Unidos en San José, Carta a Departamento de Estado, "Role of DEA [confidential]", 1977SANJO04946, Wikileaks PlusD, Kissinger Cables, 28 de octubre de 1977.

${ }^{47}$ Véase Departamento de Estado, Carta a Embajada de los Estados Unidos en Tegucigalpa, "Talks with top GOH Officials in Narcotics Control in Honduras Tegucigalpa and Mexico for DEA [confidential]", 1978STATE056149, Wikileaks PlusD, Carter Cables, 4 de marzo de 1978.

${ }^{48}$ Véase United States General Accounting Office, "Drug Control in South America...", p. 34. 
del esfuerzo metódico de los países por investirlos con adjetivos del tipo "élite", "móvil", "eficiente" y "profesional".

Grosso modo, las nuevas unidades antidrogas contaban con cuatro divisiones principales: una que se ocupaba de atender las denuncias de consumo de drogas y de venta al menudeo; otra destinada al registro y control de precursores químicos que legalmente llegaban a los respectivos países; una tercera concentrada en atender e investigar los reportes de tráfico y cultivo de drogas de alto volumen; por último, una división dedicada al tráfico internacional en puertos, terminales de avión y carreteras fronterizas. Esta última contaba, en la mayoría de los casos, con una "sección de inteligencia" que recolectaba la información del resto de las unidades y mantenía el contacto más estrecho con la DEA y las otras policías regionales. Al igual que la DEA, las nuevas unidades antidrogas mantenían dos tipos de funcionamiento: una territorial y otra especializada en los tipos de drogas. En todos los casos, se concentró la atención en las sustancias que los Estados Unidos veían como prioritarias al tiempo que se apostó por una política represiva y poco tolerante con el consumidor. De la misma manera, las nuevas policías asimilaron cargos, ceremonias y nombramientos al modo de la DEA, aun sin que los propios actores locales entendieran del todo los motivos. Esto obedece a que, como señala la teoría neoinstitucional, "las estructuras formales de muchas organizaciones [...] reflejan marcadamente los mitos de sus ambientes institucionales, más que las demandas de sus actividades de trabajo". 49

Las nuevas unidades policiacas surgieron como resultado de conflictos y disputas entre burocracias ya existentes. Con pocas excepciones, las unidades antinarcóticos continuaron funcionando bajo el control militar o al mando de militares. En los casos en que se formaron organizaciones enteramente civiles, las tareas antinarcóticos se llevaron a cabo, como en

${ }^{49}$ J. W. Meyer y B. Rowan, "Institutionalized Organizations: Formal Structure as Myth and Ceremony", The American Journal of Sociology, vol. 83, núm. 2, 1977, p. 341. 
Chile, con alguna unidad militar. En países con sembradíos importantes de mariguana, amapola y hoja de coca se planearon, además, campañas de erradicación para las que se crearon estructuras alternas: secciones de aviación y grupos de trabajo conjunto (joint task forces) que incorporaban a militares, policías locales y policías especializadas.

\section{MECANISMOS NORMATIVOS Y DE EMULACIÓN EN EL CAMBIO INSTITUCIONAL}

En la primera sección del artículo se identificó los mecanismos normativos y de emulación, a diferencia de los coercitivos, como formas suaves de cambio institucional. Se hizo hincapié en que la difusión de los modelos organizativos no se explicaría por la manipulación de incentivos o la condicionalidad, sino por los procesos de socialización a los que estuvieron expuestos actores con información incompleta, racionalidad limitada e incapacidad para calcular los costos y beneficios de cada política. En ambos casos se pone "la atracción por ciertos modelos" como matriz de su funcionamiento. De ahí que tanto los mecanismos normativos como los de emulación se hayan interpretado en los estudios sobre difusión de políticas dentro de la categoría de "aceptación social" y se los relacione con la agenda constructivista en las relaciones internacionales. ${ }^{50}$ A continuación, se explorarán tres procesos facilitados por la DEA que llevaron al desencadenamiento de dinámicas homogeneizadoras: la producción de expertos y especialistas, la organización de asociaciones y redes especializadas y la consolidación de una élite profesional. Los tres procesos se han identificado, tanto por Powell y Dimaggio, como por la bibliografía de transferencia y difusión

${ }^{50}$ F. Dobbin, B. Simmons y G. Garrett, "The Global Diffusion of Public Policies: Social Construction, Coercion, Competition, or Learning?", Annual Review of Sociology, núm. 33, 2007, p. 452. 
de políticas, como catalizadoras de dinámicas normativas y miméticas.

\section{LA PRODUCGIÓN DE EXPERTOS Y ESPECIALISTAS}

Por medio del desarrollo y financiamiento de distintos dispositivos -seminarios, escuelas especializadas, material bibliográfico, cursos y talleres-, la DEA promovió el entrenamiento de policías exclusivamente en el tema de drogas. Surgió así una nueva categoría de actores con un corpus de conocimiento específico y un capital simbólico importante en el campo policial de políticas de drogas.

El entrenamiento especializado en el tema de drogas concerniente a América Latina no comenzó con la creación de la DEA ni se limitó a los programas que impulsó la agencia a partir de 1973. Desde principios del siglo xx, y con más claridad a partir de finales de la década de los años cincuenta, los Estados Unidos hicieron, en América Latina y el resto del mundo, importantes inversiones en programas de entrenamiento, suplemento de equipo policiaco y transferencia de conocimiento a diferentes países. ${ }^{51}$ Mediante un amplio abanico de programas especiales se difundieron técnicas de vigilancia electrónica y contrainsurgencia en países que, en clave de "guerra fría", resultaban prioritarios para los Estados Unidos. ${ }^{52}$ Aunque con un papel secundario, si se lo compara con la ops y otras iniciativas, el FBN participó en los programas de modernización policiaca que surgieron a finales de la década de los años cincuenta. La punta de lanza fue la creación, en 1956, de su propia Escuela de Entrenamiento del FBN (Federal Bureau

${ }^{51}$ Véase M. K. Huggins, "U.S.-Supported State Terror: A History of Police Training in Latin America”, Crime and Social Justice, núms. 27/28, 1987, pp. 151-152. Para una perspectiva más global, cf. J. Kuzmarov, Modernizing Repression, Boston, University of Massachusetts Press, 2012. 1967.

${ }^{52}$ Office of Public Safety, "Program Guide: Program Safety Training", 
of Narcotics Training School, FBNTs). ${ }^{53}$ La FBNTS ofrecía cursos dos veces al año y contemplaba un total de veintitrés áreas distintas e incluía cursos sobre cómo llevar casos de crimen organizado a las cortes e incluso tácticas para debatir con defensores de métodos alternativos. ${ }^{54}$ En su primera década de funcionamiento, la FBNTS instruyó a más de dos mil policías estadounidenses y extranjeros. ${ }^{55}$ Para los estudiantes latinoamericanos se creó, en 1965, una escuela especial al interior de la FBNTs llamada Latin American School, de la que graduaron casi cien estudiantes durante los primeros dos años. ${ }^{56}$ La escuela tenía especial interés en la enseñanza de métodos de interrogación a sospechosos, investigaciones encubiertas -a pesar de estar prohibidas casi en todos los países de América Latina- y otros métodos de obtención de evidencia. Los policías más prestigiosos del FBN ofrecían clases magistrales en las cuales narraban episodios de su desempeño como agentes. ${ }^{57}$ Asimismo, se incluyó en la currícula una estancia en la oficina de Nueva York; allí, los estudiantes latinoamericanos podían poner en práctica lo aprendido y socializar con sus colegas estadounidenses. ${ }^{58}$ Así se forjaban relaciones con policías locales y oficiales de otros países que podían durar por décadas.

Durante la década de los años sesenta, el FBN colaboró con la International Police Academy (IPA) en la instrucción

${ }^{53}$ U.S. Bureau of Narcotics, Traffic in Opium and other Dangerous Drugs: For the Year Ended December 31, 1956, Washington, D.C., Government Printing Office, 1957, p. 62.

${ }^{54}$ N. Lee Smith, "Cured of the Habit by Force": The United States and the Global Campaign to Punish Drug Consumers, 1898-1970, tesis, The University of North Carolina at Chapel Hill, 2007, p. 221.

${ }^{55}$ Los datos de policías entrenados en la FBNTs los he obtenido de la revisión de los reportes anuales del FBN. Sobre la participación de estudiantes extranjeros, véase H. L. Giordano, Carta a Juan Barona Lobato, RG 170, Entrada 9, Caja 160, carpeta 1, NARA, 19 de enero de 1960.

${ }^{56}$ Giordano, "Inter-American Efforts Progressing Narcotics Control", International Police Academy Review, abril de 1967, p. 5.

${ }^{57}$ H. J. Anslinger, "Narcotics Bureau Conducts Training School for Police”, FBI Law Enforcement Bulletin, vol. 31, núm. 10, 1962, pp. 7-10.

${ }^{58}$ Giordano, art. cit., p. 4. 
antinarcóticos de más de mil policías provenientes de América Latina. ${ }^{59}$ De esta manera se difundieron en el subcontinente innovaciones técnicas y se proveyó a las policías locales de habilidades en administración, detección de huellas digitales, colección de información antinarcóticos, interrogación de sospechosos y negociaciones encubiertas. A principios de la década de los años setenta, los entrenamientos antinarcóticos en América Latina se vieron impulsados por la expansión del BNDD en la región y por una serie de leyes aprobadas en el Congreso de los Estados Unidos que prohibieron la asistencia policial a otros países en temas que no estuvieran relacionados con el control antidrogas. Ello provocó que mucho del presupuesto destinado a la compra de equipo para las policías extranjeras fuera canalizado a la asistencia de antinarcóticos.

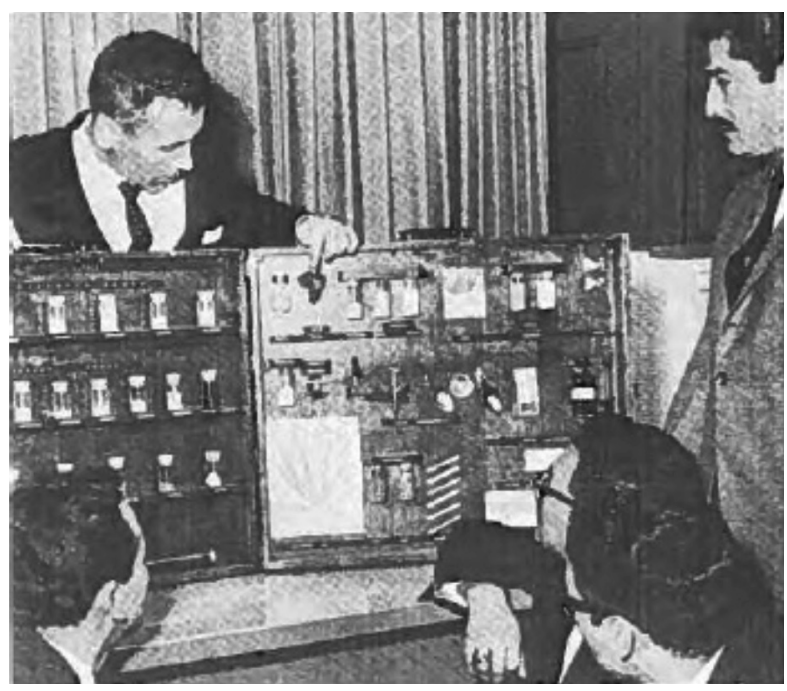

Figura 1. Agente del FBN en seminario con estudiantes latinoamericanos. Fotografía y descripción: International Police Academy Review, vol. 1, núm. 2, 1967, p. 4.

${ }^{59}$ U.S. Bureau of Narcotics, Traffic in Opium and other Dangerous Drugs: For the Year Ended December 31, 1967, Washington, D.C., Government Printing Office, 1968, p. 27. 
La creación de la DEA supuso un cambio cualitativo en la formación de agentes antinarcóticos con alto grado de especialización. A diferencia de lo que sucedía en la década de los años sesenta, los entrenamientos comenzaron a desarrollarse, casi en su totalidad, fuera de los Estados Unidos. Así, por ejemplo, tan sólo en 1973, la DEA organizó cincuenta cursos especializados alrededor del mundo. ${ }^{60}$ Ya en 1976, por cada policía entrenado en Estados Unidos, se instruía a alrededor de diez en sus respectivos países. ${ }^{61}$

La DEA construyó un sofisticado sistema de entrenamiento policial dirigido a todo tipo de funcionarios involucrados directa o indirectamente en tareas de law enforcement antidrogas. La clave para el desenvolvimiento de este sistema fue la temprana creación de una División de Entrenamiento Internacional (International Training Division, ITD). Su propósito era desarrollar, a partir de necesidades específicas, programas con objetivos y perfiles diferenciados. Mientras que algunos cursos duraban apenas unos cuantos días, otros se prolongaban por varias semanas. Los había en distintos idiomas, con diferentes grados de especialización y eran subvencionados por diversas fuentes de financiamiento. Gran parte de los esfuerzos de la ITD se concentraron en el impulso de un programa de entrenamiento basado en la idea de "equipos móviles de entrenamiento" (International Trainings Division's Mobile Teams) armados según las necesidades puntuales de cada país. Hacia finales de 1978, los equipos móviles habían logrado instruir a 8275 policías en sesenta y cinco países. ${ }^{62}$

De esta manera, durante la primera parte de los años setenta, en algunos países fueron entrenados más policías de los que realmente terminaban trabajando en labores relacio-

${ }^{60}$ DEA, "Drug Enforcement Training: The Development of Judgment", Drug Enforcement, núm. 1, otoño de 1973, p. 31.

${ }^{61}$ Departamento de Estado, Carta a Embajadas varias, "Narcotic Training Facilities", 1976STATE284346, Wikileaks PlusD, Kissinger Cables, 19 de noviembre de 1976.

${ }^{62}$ W. J. Leamy, "Drug Law Enforcement Training Builds International Cooperation”, Drug Enforcement, vol. 4, núm. 3, 1977, p. 16. 
nadas con drogas. En Bolivia, por ejemplo, de los 250 policías instruidos, apenas 130 se dedicaron a tareas relativas a antinarcóticos. En Chile, de 225 policías instruidos, únicamente 65 se consagraron a la labor referida, mientras que en Perú la proporción fue de 382 a $110{ }^{63}$ En otros países, la oferta casi igualaba la totalidad de la plantilla. En México, por ejemplo, el BNDD y la DEA habían entrenado, para 1974, a 250 de los 350 policías de los agentes antidrogas de la Policía Judicial mexicana -amén de una larga lista de psiquiatras, sociólogos y criminólogos en asuntos como adicción, armas de fuego, historia de los narcóticos, uso e identificación de drogas. ${ }^{64}$

La expansión de los programas de entrenamiento en antinarcóticos de los Estados Unidos se refleja en los números: tan sólo entre 1972 y 1978 se instruyó a 5070 policías latinoamericanos (sin incluir a México ni a América Central). De ese total, 3476 fueron entrenados por la DEA. Alrededor del 10\% asistió a escuelas en Estados Unidos; el resto, a instituciones en sus propios países. ${ }^{65}$ Mientras que ningún Estado de la región estuvo exento de estas prácticas, Argentina (544 policías), Colombia (531) y Brasil (523) fueron los países en los que la DEA fue más activa en este respecto. ${ }^{66}$ La predominancia de estos tres países no se debe a su relevancia como puntos estratégicos en el mercado de drogas, sino a la apertura que mostraron sus gobiernos, en general, al entrenamiento de sus fuerzas de seguridad.

Aunque se tenía la impresión de que los programas habían sido útiles y efectivos, hacia la segunda mitad de la década de los años setenta, la DEA reconoció internamente que era necesario cambiar de prioridades y avanzar en el desarrollo

${ }^{63}$ United States General Accounting Office, "Drug Control in South America...", p. 31.

${ }^{64}$ United States General Accounting Office, "Efforts to Stop Narcotics and Dangerous Drugs Coming from and through Mexico and Central America”, Washington, D.C., GAO, 1974, p. 27.

${ }^{65}$ Véase United States General Accounting Office, "Drug Control in South America...", p. 30.

${ }^{66} I d$. 


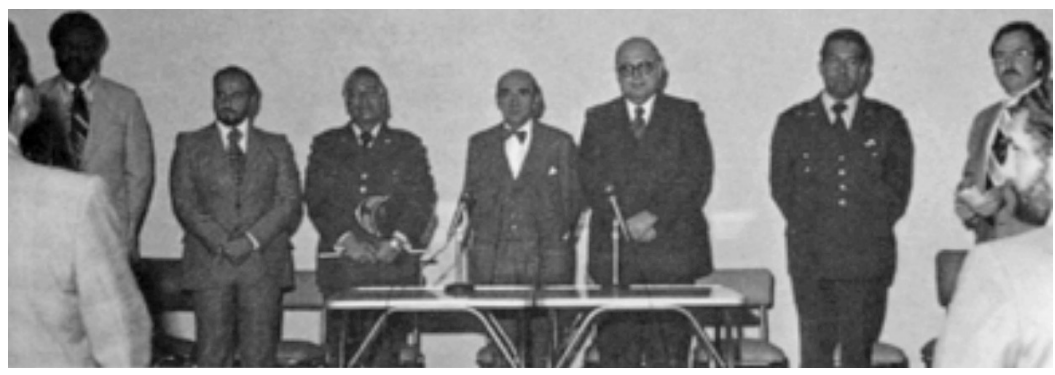

Figura 2. Inauguración de un seminario auspiciado por la DEA en Bogotá. Fuente: DEA World, vol. 4, núm. 6, 1979, p. 4. De izquierda a derecha: Líder del equipo de Glenn Brown; Dr. Mario Restrepo-Tafur, Procurador general de la policía general; Luis Felipe Estupinas-Fuentes, Jefe de Operaciones de la policía nacional de Colombia; Dr. Guillermo González-Charry, Secretario general de Colombia; Honorable Diego Asencio, Embajador de Estados Unidos; Col. Osvaldo Caraballo, Asistente jefe de la policía de Bogotá; y SAIC David Burnett.

de capacidades de las instituciones pares con el propósito de que éstas desarrollasen sus propios programas de entrenamiento policiaco en el marco de la currícula general de sus academias. ${ }^{67}$ En el marco de ese nuevo tren de prioridades, la DEA desarrolló en 1976 un programa para instructores provenientes de América Latina. ${ }^{68}$ A diferencia de los cursos básicos, la idea era que los nuevos reclutas encargados de implementar programas semejantes en sus países -normalmente supervisores o instructores- fungieran como correas de transmisión del corpus de conocimientos acumulado por la DEA. Bajo ese principio se consolidó la Advanced International School for Instructors (AIS-I), escuela cuyos cursos, de cinco semanas de duración y cualitativamente distintos al provisto por los equipos móviles de entrenamiento, se centraban en tareas de organización y desarrollo de programas an-

${ }^{67}$ Véanse Departamento de Estado, Carta a Embajadas varias, "Narcotic Training Facilities" y DEA, "Guidelines Relating to Operations in Foreign Countries (Revised)", 30 de julio de 1976.

${ }^{68}$ Departamento de Estado, Carta a Embajadas varias, "Narcotic Training Facilities". 
tinarcóticos. Como complemento, se incluía la posibilidad de hacer intercambios con diferentes oficinas de la DEA para familiarizarse con el trabajo de agentes en otras geografías. Así, poco a poco emergieron institutos de capacitación en América Latina: en Perú y México se establecieron, respectivamente, cursos especializados en la Escuela de Capacitación de la PIP y en el Instituto Técnico de la Procuraduría General de la República. De gran relevancia para la consolidación de escuelas especializadas en el continente fue la amplia bibliografía en temas referentes a drogas, en inglés y español, que la DEA llevó a cabo. Aunque se precisaría de estudios de caso para mostrar su relevancia concreta, hay pruebas del uso de manuales de iniciación y preparación de casos, métodos de obtención de evidencia, operaciones de allanamiento y manejo de evidencia física, hechos por la DEA, en las escuelas antinarcóticos en América Latina.

Visto lo anterior, puede plantearse la hipótesis de que la creación de un corpus de conocimientos específicos y la producción de actores sociales expertos en el área llevaron al desarrollo de sistemas cognoscitivos que, eventualmente, condujeron a procesos de reorganización en el campo de antinarcóticos relativamente homogéneos en América Latina.

LA ORGANIZACIÓN DE REDES Y ASOCIACIONES ESPECIALIZADAS

Se propone que la organización de asociaciones y redes especializadas de la DEA produjo un "aumento en la densidad de los contactos organizacionales" entre las nuevas unidades antinarcóticos, elemento fundamental para el desarrollo de cualquier campo organizacional. ${ }^{69}$ La formación de nuevas redes y asociaciones no disputó la posición central de la DEA

${ }^{69}$ Dimaggio, "Construcción de un campo organizacional como un proyecto profesional. Los museos de arte de los Estados Unidos, 19201940", en W. Powell y P. Dimaggio (eds.), El nuevo institucionalismo en el análisis organizacional, México, Fondo de Cultura Económica, 1999, p. 344. 
como referente del resto de las organizaciones; todo lo contrario, fortaleció las posibilidades de difusión de su modelo.

Para procurar y mantener las redes creadas durante los programas de entrenamiento, la DEA promovió el establecimiento de una asociación conformada por antiguos estudiantes de las escuelas antinarcóticos celebradas por el FBN, el BNDD y la DEA. Se la conoció como International Alumni Association (IAA). Durante su breve existencia, la IAA planeó conferencias internacionales a las que asistieron antiguos estudiantes de al menos diecinueve países distintos. ${ }^{70}$ La IAA tenía la intención no sólo de continuar con el intercambio de experiencias, sino que pretendía fundar "las bases para la creación de una comunidad internacional de law enforcement". ${ }^{71}$ Poco después de su fundación, la IAA se transformó en la International Drug Enforcement Association (IDEA), en palabras del administrador de la DEA: "una hermandad de policías extranjeros". ${ }^{72}$ IDEA mantenía una revista propia (Communique) y entendía su función como "catalizadora de la difusión de nuevas técnicas de law enforcement en el mundo". ${ }^{73} \mathrm{Al}$ finalizar la década de los años setenta, IDEA era toda una institución y celebraba reuniones periódicas en cada región; ${ }^{74}$ aglomeraba a 1345 oficiales de setenta y un países. ${ }^{75}$ A las reuniones de IDEA en América

70 DEA, “International Training Program”, Drug Enforcement, núm. 3, invierno de 1975, pp. 20-21. Véase también Departamento de Estado, "International Alumni Association Conference Rome, Italy", 1976STATE2727 72, Wikileaks PlusD, Kissinger Cables, 5 de noviembre de 1976.

${ }^{71}$ DEA, "International Training...", pp. 20-21.

${ }^{72}$ P. B. Bensinger, DEA Administrator, Southeast Asian Narcotics: Hearings before the Select Committee on Narcotics Abuse and Control, House of Representatives, Ninety-Fifth Congress, first session, July 12 and 13, 1977, U.S. Government Printing Office, 1978, p. 153.

${ }^{73}$ DEA, Office of Training, "Training Manual", 1988, p. 25.

${ }^{74}$ DEA Singapur, Carta a DEA HQS, "International Drug Enforcement Association Conference (IDEA)- Kuala Lumpur, Malaysia", 1977SINGAP 01763, Wikileaks PlusD, Carter Cables, 26 de abril de 1977.

${ }^{75}$ Francis M. Mullen, DEA Acting Administrator, Hearings before the Committee on Foreign Affairs, House of Representatives, Ninety-Seventh Congress, second session, April 20, 21, and 22, 1982, pp. 191-192. 
Latina asistían jefes policiacos de la región con un denominador común: todos ellos habían pasado por alguna escuela de instrucción de la DEA. La composición de participantes en los encuentros de Santiago en 1977, Lima, en 1978, y Caracas, en 1979, así lo demuestra.

Además de las conferencias organizadas por la agencia, la DEA apoyó a otras asociaciones especializadas cuyo trabajo aseguraba un derrotero para la homogenización de las organizaciones latinoamericanas. El caso más notable es el de la International Association of Chiefs of Police (IACP), una de las organizaciones más longevas en el campo del law enforcement y difusora de prácticas policiales desde finales del siglo XIX. ${ }^{76}$ La IACP incorporaba a jefes policiacos de todo el mundo y trabajaba con la DEA en la edición de manuales técnicos, organización de congresos y espacios informales de negociación que incrementaban los flujos de información y reforzaban la conciencia de los policías de narcóticos "en cuanto a que eran parte de una empresa colectiva". ${ }^{77}$

Asimismo, la DEA organizó encuentros regionales a los que atendían las principales figuras de las policías latinoamericanas: agentes ministeriales, coordinadores de área, jefes de unidades enteras, etc. Aunque por lo regular la organización de estos eventos corría a cargo de un gobierno en particular, la financiación se asumía en el programa antinarcóticos de los Estados Unidos. ${ }^{78}$ En todos los casos asistía algún representante regional de la DEA en calidad de observador y procuraba mantener un perfil bajo en las reuniones plenarias. Por ello, el aura de autonomía que se pensaba tenían estos encuentros era a todas luces aparente. ${ }^{79}$ Por último, las

${ }^{76}$ Nadelmann, op. cit., pp. 84-93.

${ }^{77}$ Dimaggio, art. cit., p. 345.

78 Véase, por ejemplo, Embajada de los Estados Unidos en La Paz, Carta al Departamento de Estado, "Proposal for meeting of host country drug officials [limited official use]”, 1975LAPAZ02934, Wikileaks PlusD, Kissinger Cables, 25 de abril de 1975.

${ }^{79}$ Véase, por ejemplo, Departamento de Estado, Carta a Embajadas varias, "Proposed conference of National Police Chiefs in Mexico City 
agencias estimularon el contacto entre funcionarios encumbrados en América Latina a partir de las reuniones que los agentes del BNDD y la DEA organizaban cada trimestre en algún país de América Latina -las llamadas SAIC Conferences. A estas reuniones, en las que se discutían los planes y diagnósticos regionales, asistían, además de los agentes responsables de cada país, los contactos locales más relevantes de cada uno de los directores.

En resumen, la organización de redes y asociaciones especializadas de la DEA llevó a la emergencia de redes de policías latinoamericanos que de otro modo no habrían podido establecerse. No hay evidencia de que ello haya suscitado mejores sistemas de intercambio de información; sí la hay, en cambio, de que tales espacios de diálogo difundieron el programa de la DEA en el subcontinente.

\section{Consolidación de UNA ÉLITE PROFESIONAL}

Ya la administración del FBN había elegido apoyar la consolidación de una élite profesional que, con el tiempo, pudiese adquirir relevancia al interior de sus propias organizaciones. La idea consistía en concentrar el entrenamiento en oficiales "cuyas posibilidades de crecimiento en su propio sistema fueran prometedoras". ${ }^{80}$ La estrategia buscaba "adoctrinar" a los policías en "posiciones clave" para que éstos "comenzaran a tratar sus problemas como los estadounidenses respondían a los propios". ${ }^{81}$ Así, por ejemplo, un gran triunfo del FBN había sido la colocación en 1966 de un graduado de la FBNTs como director de la policía turca. ${ }^{82}$

[confidential]", 1976STATE224576, Wikileaks PlusD, Kissinger Cables, 10 de septiembre de 1976.

${ }^{80}$ H. L. Manfredi, FBN Acting District Supervisor Rome, Carta a Henry L. Giordano, "Training Program Survey", 24 de enero de 1962. [RG 170, caja 49, carpeta 2, NARA].

81 Picini, Carta a Henry L. Giordano, "Overseas...”.

${ }^{82} I d$. 
En 1972, el BNDD instauró un programa que tenía como propósito facilitar estancias cortas a más de 200 funcionarios extranjeros de alto nivel en los Estados Unidos (Foreign Visitors Program) ${ }^{83}$ Con otra nomenclatura, el ITD retomó la iniciativa y le dio una nueva dimensión que terminó por forjar el surgimiento de una nueva élite profesional de policías antinarcóticos en América Latina. ${ }^{84}$ El Executive Observation Program (EOP), ${ }^{85}$ además de organizar viajes de funcionarios extranjeros a los Estados Unidos, asumió su "acompañamiento" y "seguimiento" por largos periodos y con beneficios tangibles: viajes a congresos, visitas a laboratorios, así como acceso a recursos e información restringida. Lo que oficialmente se describía como un proyecto encaminado al "intercambio bidireccional de ideas dirigido a resolver problemas comunes" 86 debe tenerse por herramienta para la formación de un núcleo de expertos con buenas relaciones con la agencia.

Además de familiarizar a los oficiales de alto rango con las formas operativas de la DEA, el programa permitía a los funcionarios de países periféricos conocer los proyectos fuera de los Estados Unidos que, auspiciados por la agencia, pudieran ser tenidos como referencia. Así, por ejemplo, bajo los auspicios del EOP, oficiales bolivianos y colombianos viajaron a México para conocer de primera mano la experiencia de las campañas de erradicación que se celebraron en Sinaloa. ${ }^{87}$ En un intento por favorecer estas relaciones, a finales de la

83 DEA, "A Welcome to Foreign Visitors", Drug Enforcement, núm. 2, marzo de 1974, p. 25.

${ }^{84}$ DEA, "International Training...", pp. 20-21. Véase también Departamento de Estado, Carta a Embajadas varias, "Executive Level Visitors' Program", 1975STATE169824, Wikileaks PlusD, Kissinger Cables, 18 de julio de 1975 .

${ }^{85}$ En otros lados también citado como Executive Observation Program, Executive Training Program o DEA Executive Program.

86 DEA, "A Welcome to Foreign...", p. 25.

${ }^{87}$ Véanse Embajada de los Estados Unidos en México y DEA HQS, "DEA Executive Observation Program”, 1978MEXICO04169, Wikileaks PlusD, Carter Cables, 11 de marzo de 1978, y Embajada de los Estados Unidos en Colombia, Carta al Departamento de Estado, "DEA Executive Program, Dr. 
década los Estados Unidos comenzaron a financiar y estimular "operaciones policiacas a nivel regional" hasta por tres años de duración. El éxito de tales "proyectos de cooperación” no debía juzgarse a partir del número de arrestos y drogas confiscadas; por el contrario, debía estimarse según la capacidad de la cooperación para volverse "institucionalizada y permanente". ${ }^{88}$ De esa manera se explican las similitudes operativas entre las campañas de erradicación de plantíos de droga -Bucanero, CANADOR y Fulminante-, celebradas respectivamente en Jamaica, México y Colombia durante la segunda mitad de la década de los años setenta.

Otra plataforma de la DEA por medio de la cual quería promoverse la consolidación de una élite profesional con base en atributos comunes fue la construcción de una escuela especializada, con sede en los Estados Unidos, destinada a oficiales de nivel medio-alto. En la Advanced International Drug Enforcement Training School (AIDETs) se capacitó, entre 1973 y 1978, a más de 600 funcionarios de 45 países. ${ }^{89}$ AIDETS avizoraba un objetivo a mediano plazo: tales funcionarios se convertirían en administradores y jefes policiales en sus países de origen. Muchos de ellos fueron, en efecto, aliados imprescindibles a los que no había que convencer de las bondades y beneficios de determinadas formas de operación y organización; más aún, tendieron "a considerar los problemas de manera similar, a ver las mismas políticas, procedimientos y estructuras como si estuvieran sancionados y legitimados normativamente". ${ }^{90}$ En América Latina se cumplieron las expectativas como en ninguna otra región: graduados de la AIDETs asumieron puestos clave en el cam-

Jaime Serrano Rueda", 1977BOGOTA00855, Wikileaks PlusD, Carter Cables, 27 de enero de 1977.

${ }^{88}$ Departamento de Estado, Carta a Embajada de los Estados Unidos en Panamá, "Narcotics Regional Cooperation [limited official use]", 1978STATE014730, Wikileaks PlusD, Carter Cables, 19 de enero de 1978.

${ }^{89}$ Leamy, art. cit., p. 16.

${ }^{90}$ Dimaggio y Powell, art. cit., p. 115. 
po policial antidrogas que, para finales de la década de los años setenta, tenía en la DEA su referente central.

\section{Conclusión}

La transnacionalización de la DEA estuvo motivada por una meta tan simple cuanto inalcanzable: la inmovilización de los actores sociales que producían y transportaban drogas a los Estados Unidos. Sin embargo, en ese proceso, la DEA desencadenó una serie de transformaciones deseadas y no deseadas en el resto de la estructura policial en América Latina.

En este artículo se revisó la emergencia del campo policial antidrogas en América Latina, así como el papel de la DEA en todo ese proceso. Se recurrió al nuevo institucionalismo por su capacidad para explicar e identificar la interconexión entre las organizaciones y los ambientes institucionales a su alrededor, así como la importancia de la socialización y la atracción de ciertos modelos como fuerzas que desencadenan procesos de isomorfismo institucional. Tras revisar la participación de la DEA en tres tipos de procesos, cuyo rasgo común fue el impulso de dinámicas homogeneizadoras, se probó la relevancia de la agencia estadounidense en la estructuración del campo antidrogas en América Latina.

Hasta ahora, en la bibliografía sobre políticas de droga en América Latina se había asumido que los procesos de reconfiguración policial habían sido el resultado de las presiones provocadas por el régimen global de prohibición, de mecanismos de coerción o de procesos limitados al plano doméstico. Sin pretender menoscabar la relevancia de esos factores, este artículo se concentró en explorar la puesta en marcha de mecanismos más suaves de cambio institucional y en el análisis de cierta tendencia a la homogenización de las policías antinarcóticos en América Latina.

El artículo ofrece una primera revisión de un campo de investigación todavía yermo. Faltan enfoques comparativos, 
para otros periodos, así como estudios de caso más sólidos. Abrevando del archival turn, ${ }^{91}$ que empieza a impregnar el estudio de la policía en América Latina, deberá abrirse una agenda de investigación que apueste por un diálogo productivo entre la teoría organizacional, las relaciones internacionales y las políticas de seguridad. Específicamente, nuevas investigaciones deberán analizar la alteración de los circuitos del narcotráfico y la inflación de precios de sustancias prohibidas como resultados de las políticas promovidas por la DEA.

Una interpretación crítica de los resultados de esta investigación no puede sino invitar a una reflexión más general sobre el papel de la DEA como actor clave en la difusión de patrones de gobernanza en el campo de políticas de droga en América Latina y el resto del mundo. Mediante instrumentos normativos, de emulación y de coerción, este artículo ofreció evidencia del modo en que la DEA reforzó la lógica del paradigma de la prohibición y apuntaló los principios del régimen global de prohibición. El campo policial antidrogas en América Latina no se creó como universo libre en que sus componentes fueran autónomos para elegir entre un abanico de opciones posibles, sino como constelación con dependencias claras, relaciones asimétricas distintas y capitales sociales diferenciados.

Si la guerra contra las drogas mantiene aún hoy el respaldo de gran parte de los aparatos de coerción de los estados latinoamericanos es, en cierto modo, porque la DEA, a mediados de los años setenta, hizo germinar las bases de un campo policial cuya estructura formal, programa, prácticas y propósitos responden a un paradigma anclado en la prohibición y la lógica punitiva.

91 Sobre el archival turn y los trabajos más relevantes a este respecto, véase T. Padilla y L. E. Walker, "In the Archives: History and Politics", Journal of Iberian and Latin American Research, vol. 19, núm. 1, 2013, pp. 1-10. 


\section{BibLIOGRAFÍA}

Acharya, Amitav, "How Ideas Spread: Whose Norms Matter? Norm Localization and Institutional Change in Asian Regionalism", International Organization, vol. 58, núm. 2, 2004, pp. 239-275.

Andreas, Peter y Ethan Nadelmann, Policing the Globe: Criminalization and Crime Control in International Relations, Oxford, University Press, 2008.

Anslinger, Harry J., "Narcotics Bureau Conducts Training School for Police”, FBI Law Enforcement Bulletin, vol. 31, núm. 10, 1962, pp. 7-10.

Archivo Histórico de la Policía Nacional (Guatemala).

Beckert, Jens, "Institutional Isomorphism Revisited: Convergence and Divergence in Institutional Change", Sociological Theory, vol. 28, núm. 2, 2010, pp. 150-166.

Bensinger, Peter B., DEA Administrator, Southeast Asian Narcotics: Hearings before the Select Committee on Narcotics Abuse and Control, House of Representatives, Ninety-Fifth Congress, first session, July 12 and 13, 1977, U.S. Government Printing Office, 1978.

Caiuby Labate, Beatriz y Thiago Rodrigues, "Política de drogas y prohibición en las Américas", en Beatriz Caiuby Labate y Thiago Rodrigues (eds.), Drogas, política y sociedad en América Latina y el Caribe, México, CIDE, 2015, pp. 29-52.

Campbell, John, "Institutional Reproduction and Change", en Glenn Morgan, John Campbell, Colin Crouch, Ove Kaj Pedersen y Richard Whitley (eds.), The Oxford Handbook of Comparative Institutional Analysis, Oxford, University Press, 2010, pp. 87-116.

"Convenio de proyecto entre el gobierno de los Estados Unidos de América y el gobierno del Perú”, El Peruano, 29 de agosto de 1984.

Crandall, Rusell, Driven by Drugs: U.S. Policy Towards Colombia, Boulder, Lynne Rienner Publishers, 2002.

DEA, "A Welcome to Foreign Visitors", Drug Enforcement, núm. 2, marzo de 1974, p. 25.

, "Drug Enforcement Training: The Development of Judgment”, Drug Enforcement, núm. 1, otoño de 1973, pp. 30-31. 
— (Revised)", 30 de julio de 1976.

-, "International Training Program", Drug Enforcement, núm. 3, invierno de 1975, pp. 20-21.

DEA Library, Arlington, Virginia, Estados Unidos.

DEA, Office of Training, "Training Manual”, 1988.

DEA Singapur, Carta a DEA HQS, "International Drug Enforcement Association Conference (IDEA)- Kuala Lumpur, Malaysia", 1977SINGAP01763, Wikileaks PlusD, Carter Cables, 26 de abril de 1977.

Departamento de Estado, Carta a Embajadas varias, "Executive Level Visitors' Program”, 1975STATE169824, Wikileaks PlusD, Kissinger Cables, 18 de julio de 1975.

, Carta a Embajadas varias, "Proposed conference of National Police Chiefs in Mexico City [confidential]", 1976STATE224576, Wikileaks PlusD, Kissinger Cables, 10 de septiembre de 1976. Italy",

"International Alumni Association Conference Rome,

1976STATE272772, Wikileaks PlusD, Kissinger Cables, 5 de noviembre de 1976.

- Carta a Embajadas varias, "Narcotic Training Facilities", 1976STATE284346, Wikileaks PlusD, Kissinger Cables, 19 de noviembre de 1976.

—_ Carta a Embajada de los Estados Unidos en Panamá, "Narcotics Regional Cooperation [limited official use]", 1978STATE014730, Wikileaks PlusD, Carter Cables, 19 de enero de 1978.

Carta a Embajada de los Estados Unidos en Tegucigalpa, "Talks with top GOH Officials in Narcotics Control in Honduras Tegucigalpa and Mexico for DEA [confidential]", 1978STATE056149, Wikileaks PlusD, Carter Cables, 4 de marzo de 1978.

Digital National Security Archive, Fondo Mexico-United States Counternarcotics Policy, 1969-2013, Washington, D.C.

Dimaggio, Paul, "Construcción de un campo organizacional como un proyecto profesional. Los museos de arte de los Estados 
Unidos, 1920-1940”, en Walter Powell y Paul Dimaggio (eds.), El nuevo institucionalismo en el análisis organizacional, México, Fondo de Cultura Económica, 1999.

y Walter Powell, "Retorno a la jaula de hierro. El isomorfismo institucional y la racionalidad colectiva en los campos organizacionales", en Walter Powell y Paul Dimaggio (eds.), El nuevo institucionalismo en el análisis organizacional, México, Fondo de Cultura Económica, 1999, pp. 104-125.

Dobbin, Frank, Beth Simmons y Geoffrey Garrett, "The Global Diffusion of Public Policies: Social Construction, Coercion, Competition, or Learning?", Annual Review of Sociology, núm. 33, 2007, pp. 449-472.

Embajada de los Estados Unidos en Colombia, Carta al Departamento de Estado, "Creation of Special Narcotics Unit in Attorney [limited official use]", 1977BOGOTA11749, Wikileaks PlusD, Carter Cables, 17 de diciembre de 1977.

, Carta al Departamento de Estado, "DEA Executive Program, Dr. Jaime Serrano Rueda”, 1977BOGOTA00855, Wikileaks PlusD, Carter Cables, 27 de enero de 1977.

Embajada de los Estados Unidos en Guatemala, Carta a DEA HQS, "Advanced DEA International Training School [limited official use]", 1978GUATEM01308, Wikileaks PlusD, Carter Cables, 3 de marzo de 1978.

y DEA HQS, "Request for advanced narcotics training at Guatemala [limited official use]", 1976GUATEM06877, Wikileaks PlusD, Kissinger Cables, 4 de octubre de 1974.

Embajada de los Estados Unidos en La Paz, Carta al Departamento de Estado, "DEA \& Customs CCINC Training", 1974LAPAZ06445, Wikileaks PlusD, Kissinger Cables, 4 de octubre de 1974.

, Carta al Departamento de Estado, "Proposal for meeting of host country drug officials [limited official use]", 1975LAPAZ02934, Wikileaks PlusD, Kissinger Cables, 25 de abril de 1975.

Embajada de los Estados Unidos en México y DEA HQS, "DEA Executive Observation Program", 1978MEXICO04169, Wikileaks PlusD, Carter Cables, 11 de marzo de 1978. 
Embajada de los Estados Unidos en San José, Carta a DEA HQS, "DEA In-country training for Central America”, 1976SANJO00674, Wikileaks PlusD, Kissinger Cables, 10 de febrero de 1976.

— Carta a Departamento de Estado, "Role of DEA [confidential]”, 1977SANJO04946, Wikileaks PlusD, Kissinger Cables, 28 de octubre de 1977.

Embajada de los Estados Unidos en Santiago, Carta al Departamento de Estado, "Nomination for Foreign Executive Briefing Program [limited official use]", 1976SANTIA00189, Wikileaks PlusD, Kissinger Cables, 9 de enero de 1976.

Enciso, Froylán, "Régimen global de prohibición, actores criminalizados y la cultura del narcotráfico en México durante la década de 1970”, Foro Internacional, vol. 49, núm. 3, 2009, pp. 595-637.

Fernández Labbé, Marcos, "La imaginación policial: la construcción del narcotráfico en Chile, 1900-1950", en Daniel Palma Alvarado (ed.), Delincuentes, policías y justicias: América Latina, siglos Xх y XXI, Santiago de Chile, Universidad Alberto Hurtado, 2015, pp. 330-356.

Fijnaut, Cyrille y Gary T. Marx (eds.), Undercover: Police Surveillance in Comparative Perspective, La Haya, Kluwer Law International, 1995.

Gerber, Jurg y Eric Jensen (eds.), Drug War, American Style: The Internationalization of Failed Policy and its Alternatives, Nueva York, Garland Publishing, 2001.

Giordano, Henry L., "Inter-American Efforts Progressing Narcotics Control”, International Police Academy Review, abril de 1967. , Carta a Juan Barona Lobato, RG 170, Entrada 9, Caja 160, carpeta 1, NARA, 19 de enero de 1960.

Gootenberg, Paul, "Secret Ingredients: The Politics of Coca in USPeruvian Relations, 1915-65”, Journal of Latin American Studies, vol. 36, núm. 2, 2004, pp. 233-265.

Heath, Edward Allen, Mexican Opium Eradication Campaign, tesis, California State University, 1981.

Huggins, Martha K., "U.S.-Supported State Terror: A History of Police Training in Latin America", Crime and Social Justice, núms. 27/28, 1987, pp. 149-171. 
Kuzmarov, Jeremy, Modernizing Repression, Boston, University of Massachusetts Press, 2012.

La Policía Nacional y sus estructuras, Guatemala, Archivo Histórico de la Policía Nacional, 2010.

Leamy, Walter J., "Drug Law Enforcement Training Builds International Cooperation”, Drug Enforcement, vol. 4, núm. 3, 1977, pp. 16-17.

Liga de las Naciones, Convention for Limiting the Manufacture and Regulating the Distribution of Narcotic Drugs, and Protocol of Signature, Geneva, 1931.

Manfredi, Henry L., FBN Acting District Supervisor Rome, Carta a Henry L. Giordano, "Training Program Survey", 24 de enero de 1962. [RG 170, caja 49, carpeta 2, NARA].

Mauro, Federico e Ignacio Ramírez, Historia de la droga en la Argentina. De la cocaina legal y los fumaderos a los narcos y las metanfetaminas, Buenos Aires, Aguilar, 2015.

Meyer, John W. y Bryan Rowan, "Institutionalized Organizations: Formal Structure as Myth and Ceremony", The American Journal of Sociology, vol. 83, núm. 2, 1977, pp. 340-363.

Mullen, Francis M., DEA Acting Administrator, Hearings before the Committee on Foreign Affairs, House of Representatives, Ninety-Seventh Congress, second session, April 20, 21, and 22, 1982.

Murphy, Morgan F. y Robert H. Steele (eds.), The World Narcotics Problem: The Latin American Perspective. Report of Special Study Mission to Latin America and the Federal Republic in Germany, Washington D.C., U.S. Government Printing Office, 1973.

Nadelmann, Ethan, Cops across Borders: The Internationalization of U.S. Criminal Law Enforcement, Pennsylvania, State University Press, 1993.

, "Global Prohibition Regimes: The Evolution of Norms in International Society”, International Organization, vol. 44, núm. 4, 1990, pp. 479-526.

, "The DEA in Europe", en Cyrille Fijnaut y Gary T. Marx (eds.), Undercover: Police Surveillance in Comparative Perspective, La Haya, Kluwer Law International, 1995. 
, "The DEA in Latin America: Dealing with Institutionalized Corruption", Journal of Interamerican Studies and World Affairs, vol. 29, núm. 4, 1987, pp. 1-39.

National Archives and Records Administration, Grupo 170, Records of the Drug Enforcement Administration, Subject Files of the Bureau of Narcotics and Dangerous Drugs, 1916-1970, Maryland, College Park.

Nixon, Richard, "Special Message to the Congress on Drug Abuse Prevention and Control", 17 de junio de 1971.

Office of Public Safety, "Program Guide: Program Safety Training", 1967.

\section{lombia”, abril de 1974.}

Padilla, Tanalís y Louise E. Walker, "In the Archives: History and Politics", Journal of Iberian and Latin American Research, vol. 19, núm. 1, 2013, pp. 1-10.

Pérez Ricart, Carlos A., Las agencias antinarcóticos de los Estados Unidos y la construcción transnacional de la guerra contra las drogas en México (1938-1978), tesis, Universidad Libre de Berlín, 2016.

Picini, Michael, fbn District Supervisor Rome, Carta a Henry L. Giordano, "Overseas training", 16 de marzo de 1966. [RG 170, caja 49, carpeta 2, NARA].

Poder Ejecutivo, Dof, "Código Sanitario de los Estados Unidos Mexicanos", 31 de agosto de 1934.

Rachal, Patricia, Federal Narcotics Enforcement: Reorganization and Reform, Boston, Auburn House Publishing Company, 1982.

Rico, José María, Justicia penal y transición democrática en América Latina, México, Siglo XXI, 1997.

Scott, Richard W., "Retomando los argumentos institucionales", en W. Powell y Paul Dimaggio (eds.), El nuevo institucionalismo en el análisis organizacional, México, Fondo de Cultura Económica, 1999, pp. 216-236.

Serrano, Mónica, "Unilateralism, Multilateralism, and US Drug Diplomacy. The Politics of the Certification Process in Latin America”, en Yuen Foong Khong y David Malone (eds.), Unilateralism and U.S. Foreign Policy, Boulder, Lynne Rienner Publishers, 2003, pp. 117-136. 
Smith, Nathaniel Lee, "Cured of the Habit by Force": The United States and the Global Campaign to Punish Drug Consumers, 1898-1970, tesis, The University of North Carolina at Chapel Hill, 2007.

Toro, María Celia, "Estrategias mexicanas de negociación: el caso del narcotráfico", en Ilán Bizberg (ed.), México ante el fin de la guerra fría, México, El Colegio de México, 1999, pp. 323-338.

, Mexico's "War" on Drugs: Causes and Consequences, BoulderLondres, Lynne Rienner Publishers, 1995.

United States General Accounting Office, "Drug Control in South America Having Limited Success: Some Progress but Problems are Formidable", Washington, D.C., GAO, marzo de 1978.

, "Efforts to Stop Narcotics and Dangerous Drugs Coming from and through Mexico and Central America", Washington, D.C., GAO, 1974.

, "If the United States is to develop an effective International Narcotics Control Program, much more must be done", Washington, D.C., GAO, 1975.

U.S. Bureau of Narcotics, Traffic in Opium and other Dangerous Drugs: For the Year Ended December 31, 1956, Washington, D.C., Government Printing Office, 1957.

— ded December 31, 1967, Washington, D.C., Government Printing Office, 1968.

Youngers, Colleta y Eileen Rosin (eds.), Drugs and Democracy in Latin America: The Impact of U.S. Policy, Boulder, Lynne Rienner Publishers, 2005. 